\title{
A PERFORMANCE COMPARISION BETWEEN BRUSH AND BRUSHLESS DOUBLY FED ASYNCHRONOUS GENERATORS FOR WIND POWER SYSTEMS
}

\author{
R. Carlson ${ }^{1}$, H. Voltolini ${ }^{2}$, F. Runcos ${ }^{3}$ and P. Kuo-Peng ${ }^{4}$ \\ ${ }^{1,4}$ GRUCAD/Universidade Federal de Santa Catarina \\ Campus Universitário, Trindade, 88040-900, Florianópolis, SC, BRAZIL \\ Phone/Fax number: +55 48 33694382/+55 48 2343790, ${ }^{1}$ rcarlson@ieee.org, ${ }^{4}$ patrick@grucad.ufsc.br \\ ${ }^{2}$ UTFPR \\ Av. Monteiro Lobato km 4 Ponta Grossa PR, BRAZIL \\ helio@grucad.ufsc.br \\ ${ }^{3} \mathrm{WEG}$ Indústrias S.A. \\ Avenida Prefeito Waldemar Grubba, 3300 Jaraguá do Sul - SC 89256-900 BRAZIL \\ Phone/Fax number: +55 47 3372.4460/+55 47 3724030, fredemar@weg.com.br
}

\begin{abstract}
This paper presents dynamic modeling and simulation of Brushless Doubly Fed Induction Generator (BDFIG) as an alternative for variable speed wind power applications. The mathematic models of active and reactive power for BDFIG have been developed. The power control systems of a $75 \mathrm{kVA}$ generator and wind turbine were simulated in Matlab/Simulink/SymPower Systems. The generator's control system is based on vector control principles which enable to decouple active and reactive power control. The BDFIG performance is compared to a wound rotor doubly fed induction generator. The power flow in the two generators systems and in the grid is analyzed and compared. The efficiencies of the two systems are compared.
\end{abstract}

\section{Key words}

Brushless, doubly fed induction generator, vector control, wind power.

\section{Introduction}

Doubly fed induction generators (DFIG) with a wounded rotor have been used as variable speed electric generator especially in wind power generators systems [1]. This type of generator is controlled by power converters with reduced power rating when compared with the machine electrical power output. The stator winding is connected to the electrical mains and the rotor winding is connected to a bi-directional static power converter through sliprings. The presence of slip rings reduces the life time of the machine and increases the maintenance costs. An alternative to overcome this drawback is the brushless doubly fed induction generator (BDFIG) [2-4]. The BDFIG has its origins in the technology of cascade induction machines and consists in two three-phase windings with different number of pole pairs in the stator and a special rotor cage. The power and the control windings are connected to the three-phase power supply; the power winding is connected directly while the control winding is connected through an $\mathrm{AC} / \mathrm{DC} / \mathrm{AC}$ bidirectional static power converter. In this configuration, as is the case for the doubly-fed induction machine with

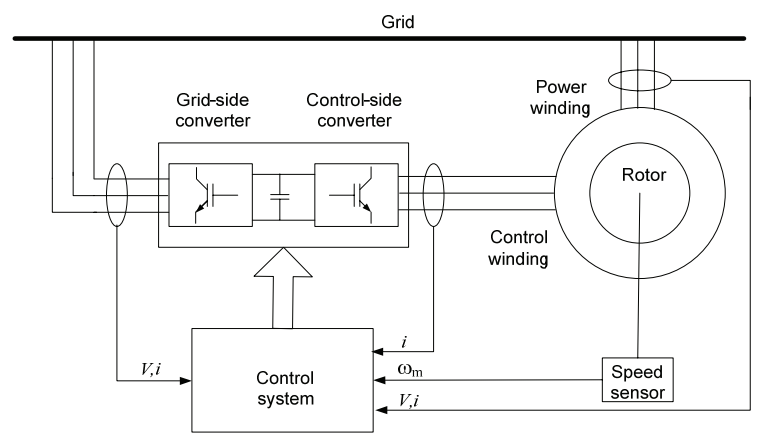

Fig. 1 - Control system for both the DFIG and the BDFIG.

brushes, the converter rating required is only the slipfraction of the machine capacity and with the appropriate control, the active and reactive power can be regulated above and bellow the synchronous speed of the machine [2][4]. A general scheme of the DFIG and BDFIG control system is shown in Fig. 1. The control winding represent the rotor winding for the DFIG and the control winding for the BDFIG, respectively.

The DFIG is a well known drive technology with excellent control behavior [1].

For the BDFIG the major interest is the operation in synchronous mode. The synchronous operation occurs when the two stator windings share a rotor current of the same frequency. The synchronous operation requires that the control winding frequency be adjusted to every rotor speed. There is no alternative of operation which is not the synchronous one, because otherwise the machine could not operate smoothly due to the torque pulsation generated by the control winding.

In the synchronous mode, the cross-coupling between control and power windings is only guaranteed if both windings induce equal rotor frequencies:

$$
\omega_{r p}=\omega_{r a}
$$


where $\omega_{p}=\omega_{r p}+p_{p} \omega_{r}$ and $\omega_{a}=-\omega_{r a}+p_{a} \omega_{r}$

In (2), $\omega_{r p}$ and $\omega_{r a}$ are the induced rotor frequencies for power and auxiliary windings, $\omega_{p}$ and $\omega_{a}$ are the power and auxiliary windings frequencies, $\omega_{r}$ is the rotor speed, $p_{p}$ and $p_{a}$ are the pole-pairs of the power and auxiliary windings. The synchronous mode is guaranteed if the converter imposes frequency $\omega_{a}$ given by:

$$
\omega_{a}=\left(p_{p}+p_{a}\right) \omega_{r}-\omega_{p}
$$

The vector control system for both generators was developed for grid-side and control-side converters and was simulated in Matlab/Simulink/SymPower System.

Why is the BDFIG not used until today? This is a difficult question to answer. Most of the studies up to this day where essentially academic, dealing with small power prototypes which did not allowed to really evaluate the main advantages and disadvantages of the BDFIG compared to the DFIG. In this paper, some results will be presented based on a $75 \mathrm{~kW}$ BDFIG prototype that should contribute to a better understanding of its performance.

\section{The Machine Models}

The DFIG model in dq synchronous reference frame $\omega_{e}$ are shown in Eq. (4). The subscripts $s$ and $r$ refer to stator and rotor parameters.

For the BDFIG the mathematical machine model in dq reference synchronous frame $\omega_{e}$ is presented in Eq. 5 . The subscripts $p, a$ and $r$ refer to power winding, auxiliary (or control) winding and rotor winding quantities and $\mathrm{p}_{\mathrm{pa}}=\left(\mathrm{p}_{\mathrm{p}}+\mathrm{p}_{\mathrm{a}}\right)$.

\section{Comparative analysis between DFIG and BDFIG}

\section{A. The BDFIG prototype.}

The results presented in this paper concern a built prototype with the following characteristics:
- Main stator winding: $75 \mathrm{~kW}, 254 / 440 \mathrm{~V}, 12$ poles, $60 \mathrm{~Hz}$, concentric, three-phase, two layers, connection $2 \Delta / 2 \mathrm{Y}, 144$ slots;

- Control stator winding: $25 \mathrm{~kW}, 690 / 1200 \mathrm{~V}, 8$ poles, $60 \mathrm{~Hz}$, concentric, three-phase, two layers, connection $2 \Delta / 2 \mathrm{Y}, 144$ slots.

- Rotor winding: concentric, 10 poles, 11 slots per pole (Fig. 2).

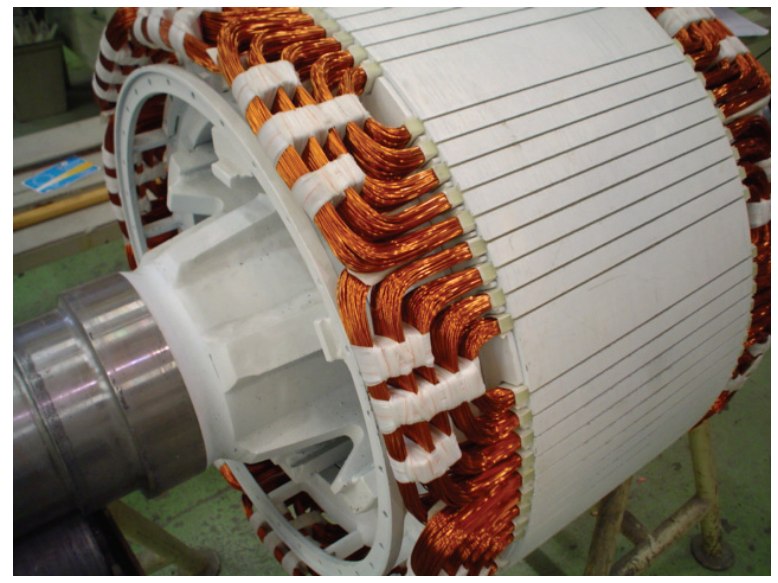

Fig. 2 - Picture of the rotor 'wounded' cage.

In order to compare with the BDFIG performance a wound rotor generator was considered with the following data:

- Stator winding: $75 \mathrm{~kW}, 254 / 440 \mathrm{~V}, 20$ poles, $60 \mathrm{~Hz}$, concentric, three-phase, connection $2 \Delta / 2 \mathrm{Y}$;

- Rotor winding: $1200 \mathrm{~V}, 60 \mathrm{~Hz} 20$ poles, connection $2 \Delta / 2 \mathrm{Y}$.

\section{B. Power Flow in the generators systems}

Initially, the whole system was simulated in three points of operation. In variable speed wind power systems, a speed range of $\pm 30 \%$ around the synchronous speed is acceptable. For the generator prototype rotor speeds of $252 \mathrm{rpm}, 360 \mathrm{rpm}$ and $468 \mathrm{rpm}$ were chosen to take measurements of active and reactive power at the power winding, the control winding and the system output

$$
\left[\begin{array}{c}
v_{q s} \\
v_{d s} \\
v_{q r} \\
v_{d r}
\end{array}\right]=\left[\begin{array}{cccc}
\left(r_{s}+p L_{s}\right) & L_{s} \omega_{e} & p L_{m} & L_{m} \omega_{e} \\
-L_{s} \omega_{e} & \left(r_{s}+p L_{s}\right) & -L_{m} \omega_{e} & p L_{m} \\
p L_{m} & \left(\omega_{e}-P \omega_{m}\right) L_{m} & \left(r_{r}+p L_{r}\right) & \left(\omega_{e}-P \omega_{m}\right) L_{r} \\
-\left(\omega_{e}-P \omega_{m}\right) L_{m} & p L_{m} & -\left(\omega_{e}-P \omega_{m}\right) L_{r} & \left(r_{r}+p L_{r}\right)
\end{array}\right]\left[\begin{array}{c}
i_{q s} \\
i_{d s} \\
i_{q r} \\
i_{d r}
\end{array}\right]
$$

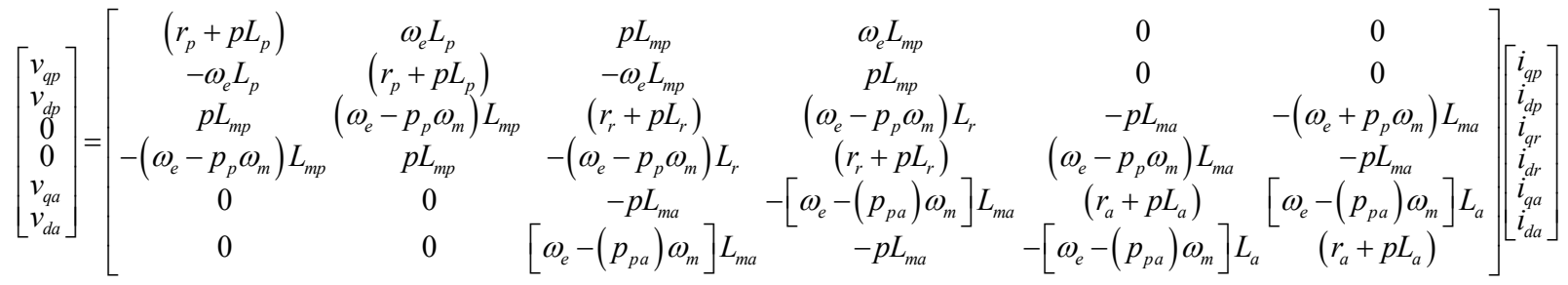


TABLE I - Power Flow in the System

\begin{tabular}{|c|c|c|c|c|c|c|c|c|c|c|c|c|c|c|c|c|}
\hline \multirow{2}{*}{$\begin{array}{l}\text { Wind } \\
\text { speed } \\
(\mathrm{m} / \mathrm{s})\end{array}$} & \multirow{2}{*}{$\begin{array}{c}\text { Generator } \\
\text { speed } \\
(\mathrm{rpm})\end{array}$} & \multirow{2}{*}{$\begin{array}{c}\text { Pmec } \\
\text { (kW) }\end{array}$} & \multicolumn{2}{|c|}{$\begin{array}{c}\text { Ppower } \\
\text { (kW) }\end{array}$} & \multicolumn{2}{|c|}{$\begin{array}{c}\text { Qpower } \\
\text { (kVAr) }\end{array}$} & \multicolumn{2}{|c|}{$\begin{array}{c}\text { Pcontrol } \\
\text { (kW) }\end{array}$} & \multicolumn{2}{|c|}{$\begin{array}{c}\text { Qcontrol } \\
\text { (kVAr) }\end{array}$} & \multicolumn{2}{|c|}{$\begin{array}{l}\text { Pconv. } \\
\text { (kW) }\end{array}$} & \multicolumn{2}{|c|}{$\begin{array}{l}\text { Qconv. } \\
\text { (kVAr) }\end{array}$} & \multicolumn{2}{|c|}{$\begin{array}{l}\text { Pgrid } \\
\text { (kW) }\end{array}$} \\
\hline & & & FIG & & DFIG & BDFIG & DFIG & BDFIG & DFIG & BDFIG & DFIG & BDFIG & DFIG & BDFIG & DFIG & BDFIG \\
\hline & & & 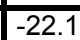 & & 14.6 & & 7.5 & 8.1 & 14.0 & 23.0 & 9 & 9 & -14.6 & & 8 & -13.0 \\
\hline & & & & & 18 & & 1. & & & 0 & 2. & & & -24.0 & -42.7 & -41.9 \\
\hline 12.0 & & 100.0 & -75.3 & -74.0 & 26.1 & 24.0 & -20.5 & -21.3 & -15.5 & -28.6 & -19.5 & -20.3 & -26.1 & -24.0 & -94.8 & -94.3 \\
\hline
\end{tabular}

(grid). A wind turbine was used in the simulation as the source of torque for the generator and the generator rotor speed was controlled in each of those three points mentioned above. The active and reactive power values, as represented in Fig. 3 are presented in table I.

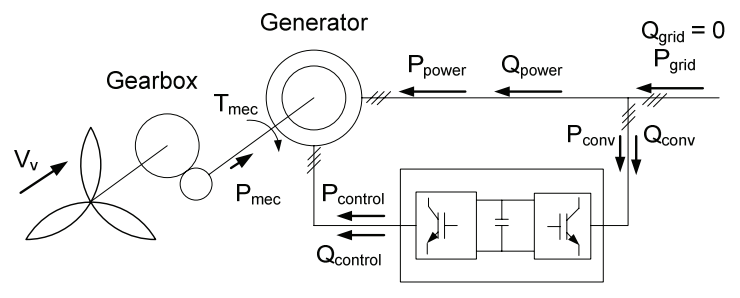

Fig. 3. Representation of the power flow on the simulated system.

Over all speed range both control-side and grid-side converters are participating to the grid power factor regulation such that the RMS value of the current of the two converters is the same.

From Table I it is clear that at all three simulated points, the active power of the DFIG and BDFIG are comparable. For the operation at synchronous speed the reactive power of both generators is zero. At 252 (subsynchronous speed) and $468 \mathrm{rpm}$ (super-synchronous speed), the reactive power flowing in the control winding of the BDFIG is larger than in the DFIG.

\section{Performance comparison between DFIG and BDFIG over all the speed range.}

For an effective comparison between DFIG and BDFIG the results were obtained for the whole speed range. The wind speed was varied linearly from 6.5 up to $12 \mathrm{~m} / \mathrm{s}$ in the time interval of the $27.7 \mathrm{~s}$. This resulted in a speed varying from 252 to $468 \mathrm{rpm}$ in this time interval. Fig. 4 represents the wind speed and the generator speed as a function of time.

The shaft mechanical torque and power are shown in Fig. 5. The mechanical torque varies from 591 N.m for a wind speed of $6.5 \mathrm{~m} / \mathrm{s}$ up to 2042 N.m for a wind speed of the $12 \mathrm{~m} / \mathrm{s}$. The mechanical power varies from 15.6 $\mathrm{kW}$ up to $100 \mathrm{~kW}$ as shown in Fig. 5.

Fig. 6 shows the RMS current in the control and power windings and in the grid of both generators. The BDFIG control winding current is $47 \%, 30 \%$ and $20.8 \%$ larger than the DFIG control winding current at 252, 360 and
$468 \mathrm{rpm}$, respectively. These results show that the BDFIG converters must be designed for a RMS current $20.8 \%$ larger than they would be for the DFIG system. The RMS currents in the power winding and in the grid of both systems have a smaller difference over all the speed range operation.

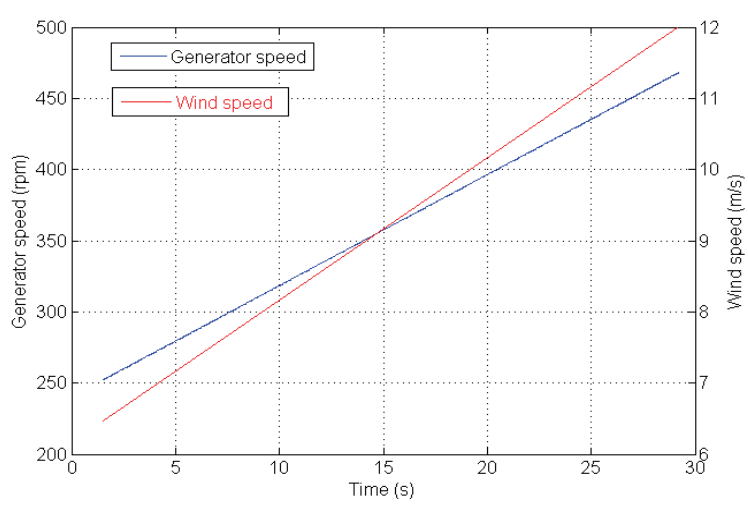

Fig. 4. Wind speed and generator speed.

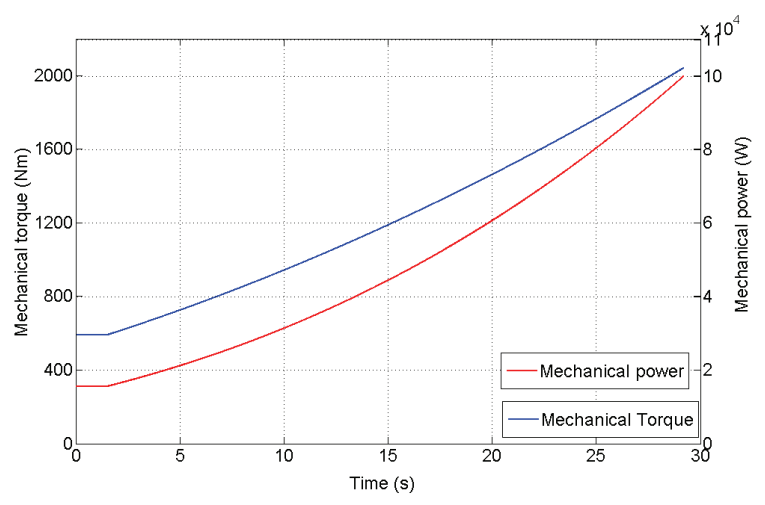

Fig.5. Shaft mechanical torque and power.

Fig. 7 and 8 shows the active power in DFIG and BDFIG systems. According to these results, there are no significant differences in the active power flow in the control winding on both systems.

The reactive power flowing in the control and power windings of both systems is presented in Fig. 9. This figure shows that the reactive power in the control windings of the BDFIG and the DFIG are positive (entering the control winding) and decrease with the speed up to the synchronous speed. At this point there is no reactive power flow in the control winding. From the synchronous speed on they are negative (out of the control winding) and increase with the speed. 
The reactive power flowing in the control winding of the BDFIG is always larger than on the DFIG, except at synchronous speed.

The reactive power flowing in the control and power windings of both systems is presented in Fig. 9. This figure shows that the reactive power in the control windings of the BDFIG and the DFIG are positive (entering the control winding) and decrease with the speed up to the synchronous speed. At this point there is no reactive flow in the control winding. From the synchronous speed on they are negative (out of the control winding) and increase with the speed. The reactive power flowing in the control winding of the BDFIG is always larger than on the DFIG, except at synchronous speed.

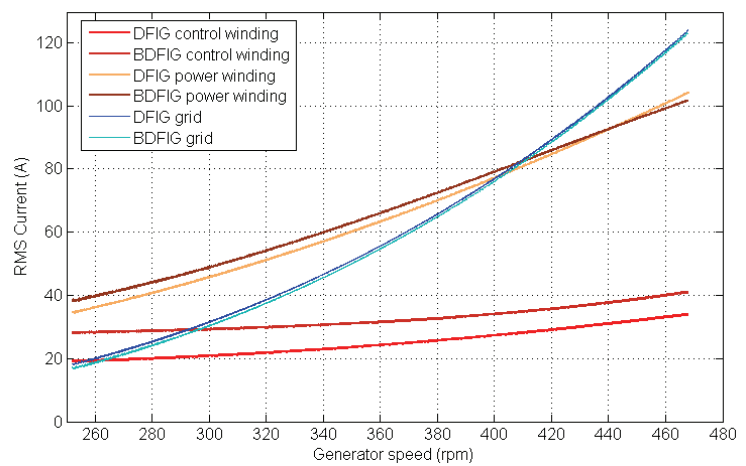

Fig. 6. RMS currents.

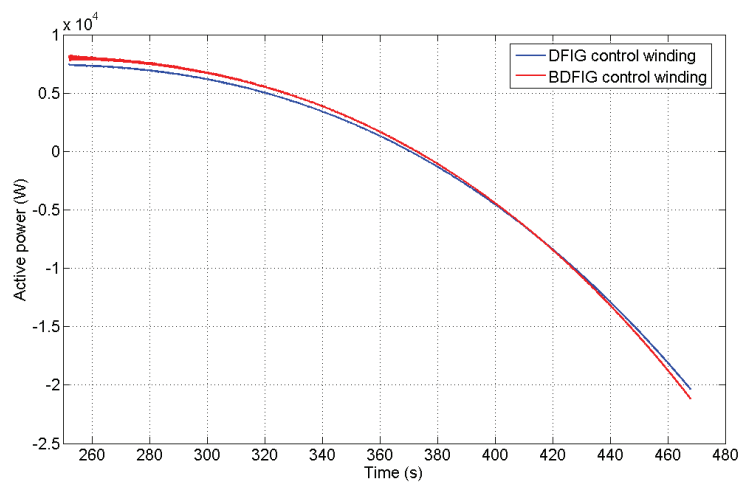

Fig. 7. Active power flowing in the control windings.

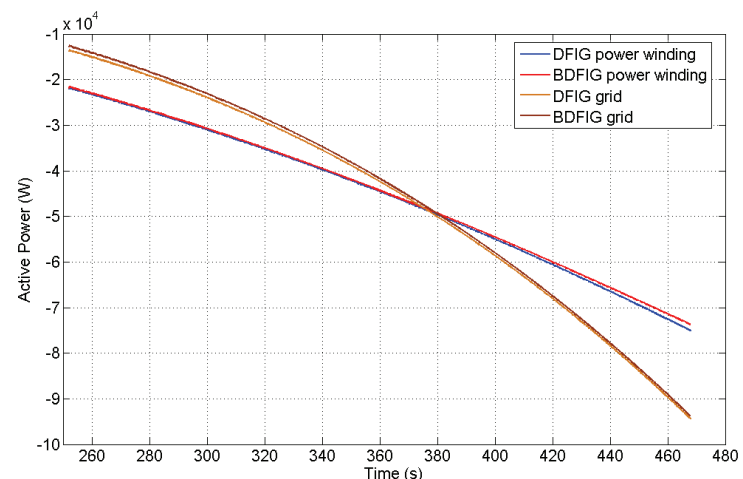

Fig. 8. Active power flow in the power winding and grid.
Fig. 10 shows the apparent power in the control and power winding and in the grid for both systems. For the control winding, the difference between DFIG and BDFIG apparent power is a minimum (near zero) at the synchronous speed and increases when the speed decreases or increases. The apparent power of the power windings and of the grid for DFIG and BDFIG are comparable.

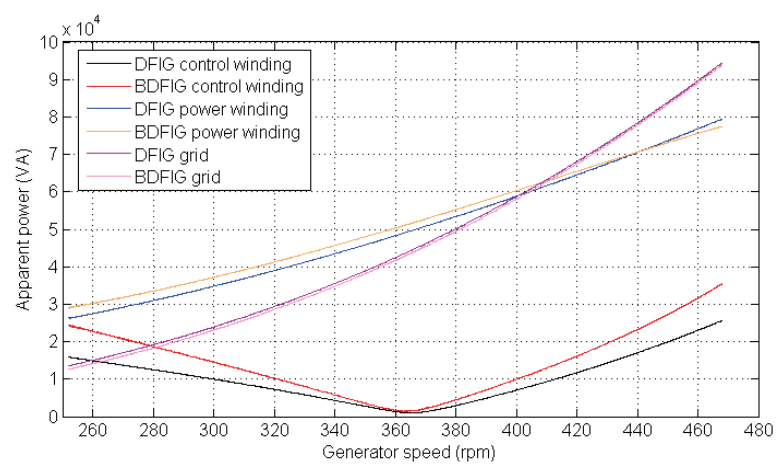

Fig. 10. Apparent power flow.

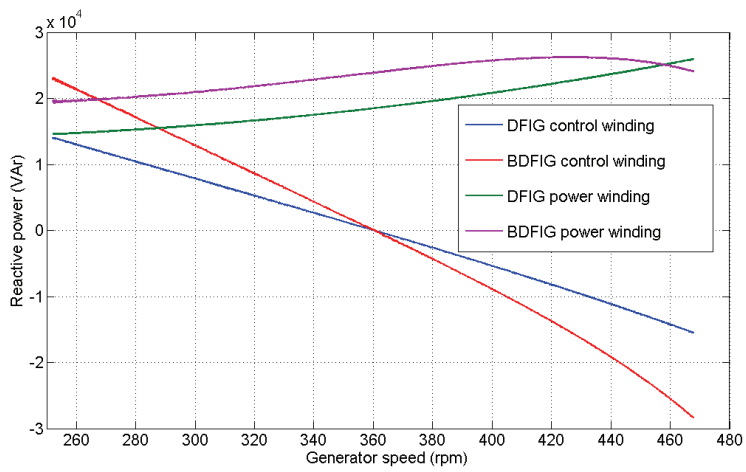

Fig. 9. Reactive power flow.

The phase A current in the control winding of both the DFIG and the BDFIG and the speed of operation during the wind speed increase are shown in Fig. 11. For both generators, the control winding current increases with the speed and are DC quantities at synchronous speed (360 rpm). This shows the smooth operation of the vector control of the control-side PWM converter.
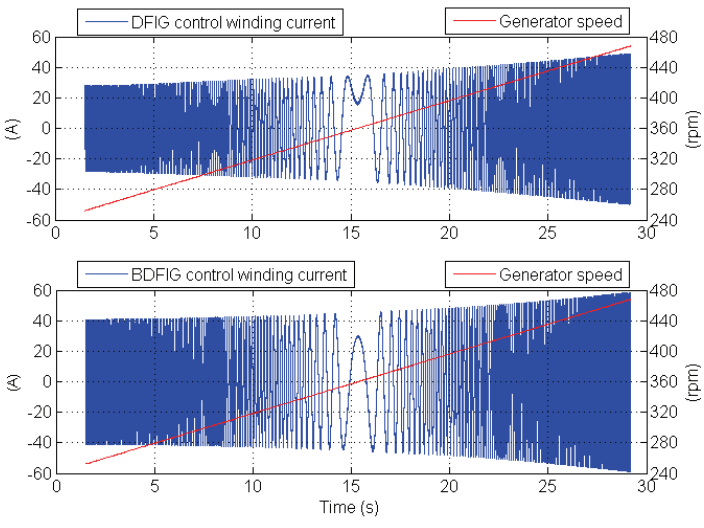

Fig. 11. Phase A control winding current. 
The efficiency of both systems was obtained dividing the grid power by the mechanical power in the generator shaft and is represented in Fig. 12. The DFIG efficiency, as expected, is better over all the speed range. In rated conditions (468 rpm), the efficiency of both systems is approximately 0.94 .

The BDFIG efficiency is worst than that of the DFIG at lower speeds. At the minimum speed of operation (252 $\mathrm{rpm}$ ) it is 0.81 while that of the DFIG is 0.87 , which means $7 \%$ lower.

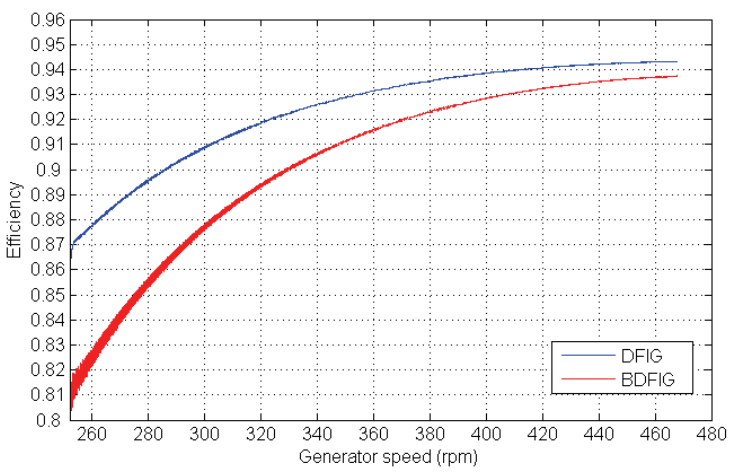

Fig. 10. Efficiency.

This efficiency analysis does not consider the generators iron losses as well as the mechanical losses. The measured losses for the brushless generator and the usual losses of brush generators of the same power already made-up at WEG Industries are presented in Table II. It is evident from these data that the brushless machine presents higher iron and mechanical losses. But a full comparison of the respective life long efficiencies, yet to be made, should take into account the reduction in long term maintenance due to the elimination of the brushes. In table II, subscripts 1 and 2 refer to stator and rotor, respectively.

TABLE II. - Power losses in the BDFIG and DFIG.

\begin{tabular}{|l|c|c|c|c|}
\cline { 2 - 5 } \multicolumn{1}{c|}{} & \multicolumn{2}{c|}{ DFIG 75 kW 360 rpm } & \multicolumn{2}{c|}{ BDFIG 75 kW 360 rpm } \\
\hline $\mathbf{P}_{\text {Joule1 }}(\mathbf{k W})$ & 3.22 & $43.70 \%$ & 5.13 & $58.88 \%$ \\
\hline $\mathbf{P}_{\text {Joule2 }}(\mathbf{k W})$ & 2.82 & $38.30 \%$ & 0.95 & $10.90 \%$ \\
\hline $\mathbf{P}_{\text {iron }}(\mathbf{k W})$ & 0.51 & $6.90 \%$ & 1.17 & $13.40 \%$ \\
\hline $\mathbf{P}_{\mathbf{S}}(\mathbf{k W})$ & 0.41 & $5.60 \%$ & 0.72 & $8.22 \%$ \\
\hline $\mathbf{P}_{\text {Mec }}(\mathbf{k W})$ & 0.41 & $5.50 \%$ & 0.75 & $8.60 \%$ \\
\hline $\mathbf{P}_{\text {TOTAL }}(\mathbf{k W})$ & 7.37 & $100 \%$ & 8.72 & $100 \%$ \\
\hline
\end{tabular}

\section{CONCLUSION}

In this paper the vector control of the BDFIG and DFIG system was implemented in Matlab/Simulink/SymPower System and an effective comparison between the generators was realized in whole speed range operation in wind power application system. The results were obtained with the two converters (control-side and gridside PWM converters) compensating reactive power in the grid. This enables the operation of the converters with equal RMS current.
The presented results show that the BDFIG converters must be designed for a RMS current $20.8 \%$ larger than they would be for the DFIG system as the rms current in the control winding is larger in the BDFIG. Apart from this, all other currents are alike.

The main disadvantage of the BDFIG face to the DFIG is the efficiency. The minimum efficiency of both systems occurs at the lower speed limit of $252 \mathrm{rpm}$ and at this point the efficiency of the BDFIG is only $7 \%$ lower than that of the DFIG. At rated speed of $468 \mathrm{rpm}$, the DFIG and BDFIG efficiencies are 0.943 and 0.937, respectively, meaning that the BDFIG efficiency would be only $0.6 \%$ lower.

The presented comparisons show that the brushless doubly fed induction generator is a viable solution for replacing the usual doubly fed induction generator.

\section{References}

[1] R. Pena, J. C. Clare, G.M Asher, "Doubly fed induction generator using back-to-back PWM converter and its application to variable-Speed wind-energy generation." IEE Proc.-Electr. Power Appl., Vol. 143, No. 3, May 1996.

[2] S. Bhowmik, R. Spée and J. H. R. Enslin, "Performance Optimization for doubly fed wind power generation systems", IEEE Transactions on Industry Applications, v 35, No 4, Jul/Aug, pp 949-958, 1999

[3] Boger, M. Wallace, A. "Performance capability analysis of the brushless doubly-fed machine as a wind generator", $7^{\circ}$ Int. Conf. Electrical Machines and Drives, 1995, pp 458461, Durham, UK, 1995

[4] F. Rüncos, R. Carlson, A.M. Oliveira, P. Kuo-Peng, N. Sadowski, "Performance analysis of a brushless double fed cage induction generator", Nordic Wind Power Conference, 1/2 March 2004, Göeteborg, Sweden. 